\title{
Eupalinolide O, a novel sesquiterpene lactone from Eupatorium lindleyanum DC., induces cell cycle arrest and apoptosis in human MDA-MB-468 breast cancer cells
}

\author{
BO YANG* , YAPING ZHAO*, CHENGHUA LOU and HUAJUN ZHAO \\ College of Pharmaceutical Sciences, Zhejiang Chinese Medical University, Hangzhou, Zhejiang 310053, P.R. China
}

Received April 7, 2016; Accepted May 17, 2016

DOI: $10.3892 /$ or.2016.5115

\begin{abstract}
Sesquiterpene lactones have been confirmed to have potential antitumor activity. Here, we demonstrated that Eupalinolide O (EO), a novel sesquiterpene lactone isolated from Eupatorium lindleyanum DC., showed significant anticancer activity against human MDA-MB-468 breast cancer cells. The cytotoxicity induced by EO was mediated by induction of apoptosis. Flow cytometric analysis demonstrated that EO treatment resulted in loss of the mitochondrial membrane potential in cancer cells which is regarded as a hallmark of apoptosis. Further study demonstrated that EO induced apoptotic cell death in the MDA-MB-468 cells through the activation of caspases. The effect of $\mathrm{EO}$ on the induction of apoptosis was significantly prevented by the treatment of pan-caspase inhibitor Z-VAD-FMK. We also found that EO treatment resulted in cell cycle arrest in the G2/M phase. The expression of cell cycle-related proteins (cyclin B1 and cdc2) was significantly decreased. Furthermore, the suppression of the Akt pathway in the MDA-MB-468 cells was observed. Collectively, EO suppressed the growth of the MDA-MB-468 cells possibly by cell cycle arrest in the $\mathrm{G} 2 / \mathrm{M}$ phase and the induction of caspase-dependent apoptosis. These results suggest that EO is a promising natural compound for breast cancer therapy.
\end{abstract}

\section{Introduction}

Breast cancer is one of the most common malignancies among women, in both developed and developing countries, accounting for $23 \%$ (1.38 million) of the total new cancer

Correspondence to: Professor Huajun Zhao or Dr Chenghua Lou College of Pharmaceutical Sciences, Zhejiang Chinese Medical University, 548 Bin Wen Road, Hangzhou, Zhejiang 310053, P.R. China E-mail: zhj@zcmu.edu.cn

E-mail: lou.chenghua@hotmail.com

${ }^{*}$ Contributed equally

Key words: breast cancer, Eupalinolide O, apoptosis, cell cycle cases and $14 \%(458,400)$ of the total cancer-related deaths in $2008(1,2)$. There are conventional strategies for breast cancer treatment, including surgery, radiotherapy, chemotherapy, hormone therapy and targeted biological therapy (3). Although recent years have seen tremendous progress in the treatment of breast cancers (4), controversies remain, patients continue to die, and a cure remains elusive (5). Therefore, the development of new anticancer agents for breast cancer is important to reduce the mortality caused by this disease.

Natural products are an important source of promising leads for the development of novel cancer therapeutics, because of their potential anticancer properties and few side effects (6-8). It is well known that vinblastine, vincristine, paclitaxel, and camptothecin have been widely applied as typical examples of plant-derived anticancer drugs in the clinic (9-11). Therefore, it is very important to develop new anticancer drugs from natural products.

Eupatorium lindleyanum DC. (Compositae), called 'Ye-Ma-Zhui' by local residents, is a perennial herbaceous plant. It has been used to treat cough and tracheitis due to its antimicrobial, antihistamine and anti-inflammatory activities (12-14). Many compounds have been isolated from this plant, including alkaloids, flavonoids, esters and sesquiterpenes $(12,15,16)$. Pharmacological studies have demonstrated a variety of biological activities of this plant $(12,15,17)$. However, there is little information concerning its anticancer activity.

In this study, the authors investigated the anticancer effect of Eupalinolide O (EO) (Fig. 1A), a novel sesquiterpene lactone isolated from the Eupatorium lindleyanum DC., on human breast cancer in vitro. Notably, EO showed significant anticancer activity against human breast cancer cells. EO suppressed cell proliferation, induced apoptosis and arrested the cell cycle at the G2/M phase in MDA-MB-468 cells. Furthermore, the authors found that the induction of apoptosis by EO was performed in a caspase-dependent manner.

\section{Materials and methods}

Cell culture and reagents. The human breast cancer cell line MDA-MB-468 was purchased from the Cell Bank of the Institute of Biochemistry and Cell Biology, Chinese Academy of Sciences (Shanghai, China) and stored in liquid nitrogen. Cells were cultured in Dulbecco's modified Eagle's medium (DMEM) culture medium containing 10\% fetal 
bovine serum (FBS; both from Gibco, USA), $100 \mathrm{U} / \mathrm{ml}$ penicillin $\mathrm{G}, 2.5 \mu \mathrm{g} / \mathrm{ml}$ amphotericin B and $100 \mu \mathrm{g} / \mathrm{ml}$ streptomycin (complete medium) at $37^{\circ} \mathrm{C}$ with $5 \% \mathrm{CO}_{2}$ in a humidified atmosphere.

3-(4,5-Dimethyl-2-thiazolyl)-2,5-diphenyl-2H-tetrazolium bromide (MTT) and dimethyl sulfoxide (DMSO) were purchased from Sigma-Aldrich (St. Louis, MO, USA). Propidium iodide (PI)/RNase staining kit and Annexin V-FITC/7AAD kit were purchased from BD Pharmingen (San Diego, CA, USA). Antibodies against caspase-3 (\#9662), cleaved caspase-3 (Asp175,\#9664), cdc2 (\#9116), phospho-Akt (Ser473/Thr308, \#9275), Akt (pan, \#4691), phospho-cdc2 (Tyr15, \#4539), PARP (\#9532), cyclin B1 (\#12231), Bcl-2 (\#2870), Bcl-xL (\#2764), caspase-8 (\#4790), caspase-9 (\#9508), cleaved caspase-9 (Asp330, \#9501), $\beta$-tubulin (\#2128), and horseradish peroxidase-conjugated secondary antibodies were purchased from Cell Signaling Technologies (Beverly, MA, USA). Bad (N-term, 1541-1) was purchased from Abcam (Cambridge, UK).

Cell viability assay. The viability of cells treated with or without EO was measured by MTT assay. The MDA-MB-468 cells were placed into 96-well plates at a final concentration of $5 \times 10^{3}$ cells/well in complete medium, and allowed to attach for $24 \mathrm{~h}$. Subsequently the cells were treated with a range of concentrations of EO for 24,48 and $72 \mathrm{~h}$, then $20 \mu 1$ MTT solution $(5 \mathrm{mg} / \mathrm{ml})$ was added, and the cells were incubated for another $4 \mathrm{~h}$ at $37^{\circ} \mathrm{C}$ in the dark. Formed formazan crystals were dissolved in $100 \mu \mathrm{l}$ DMSO and the absorbance was measured at $570 \mathrm{~nm}$ on a microplate reader (Bio-Rad, USA). The $\mathrm{IC}_{50}$ value was calculated by GraphPad Prism 5.0 software (GraphPad Software, Inc., San Diego, CA, USA).

Flow cytometric analysis of cell cycle arrest and apoptosis. Cells were plated in 6 -well plates $\left(3 \times 10^{5}\right.$ cells/well) and treated with varying concentrations of EO for $72 \mathrm{~h}$. For cell cycle analysis, cells were harvested, washed twice with ice-cold PBS and fixed in $70 \%$ ethanol at $4^{\circ} \mathrm{C}$ overnight, and stained with PI/RNase $\left(0.5 \mathrm{ml} / \mathrm{test}, 1 \times 10^{6}\right.$ cells) for $15 \mathrm{~min}$ at room temperature before analysis. To quantify the apoptotic cells, the treated cells were washed twice with ice-cold PBS and stained with Annexin-V-FITC/7AAD according to the manufacturer's instructions. Samples were subsequently analyzed by flow cytometer (Guava Technologies; Merck KGaA, Darmstadt, Germany) and DNA content was quantified using ModFit software.

Evaluation of mitochondrial membrane potential $(\Delta \psi m)$. The MDA-MB-468 cells $\left(3 \times 10^{5}\right)$ were seeded in 6-well plates for $24 \mathrm{~h}$ before the experiment. After the treatment with 2, 4, and $8 \mu \mathrm{M} \mathrm{EO}$ for $24 \mathrm{~h}$, cells were harvested, washed twice with ice-cold PBS, and incubated with JC-1 $(10 \mu \mathrm{g} / \mathrm{ml})$ in the dark for $15 \mathrm{~min}$ at $37^{\circ} \mathrm{C}$. Cells were washed three times with ice-cold PBS and analyzed by flow cytometry using emission wavelengths of $590 \mathrm{~nm}$ and $529 \mathrm{~nm}$.

Western blot analysis. Cells were harvested, washed twice with ice-cold PBS after treatment with EO, lysed by incubation in RIPA buffer containing a protease inhibitors cocktail $(1 \mathrm{mM}$ phenylmethanesulfonyl fluoride and $1 \mu \mathrm{g} / \mathrm{ml}$ leupeptin) and a

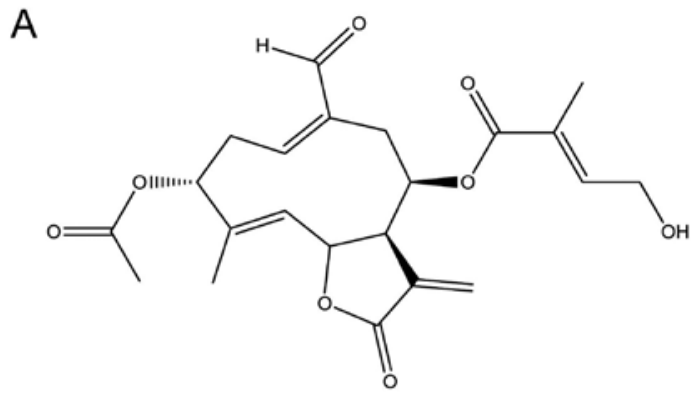

B

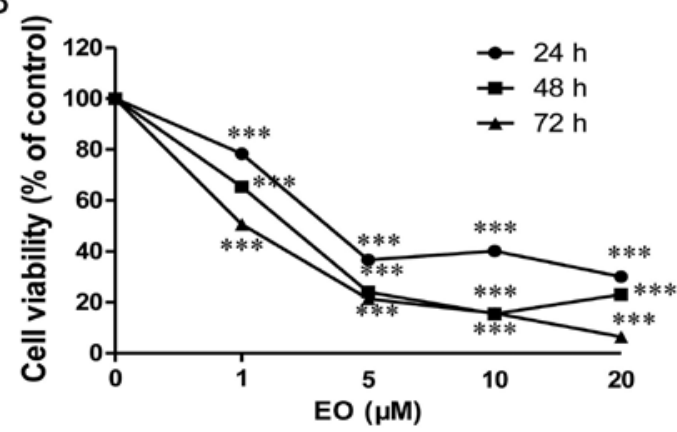

Figure 1. The cytotoxic effect of Eupalinomide O (EO) on MDA-MB-468 breast cancer cells. (A) Chemical structure of EO. (B) Effects of EO on MDA-MB-468 breast cancer cells. The MDA-MB-468 cells were treated with indicated concentrations of EO for 24, 48 and $72 \mathrm{~h}$. Cell viability was quantified by the MTT assay. Data are presented as the mean \pm SD of at least three independent experiments. ${ }^{* * * *} \mathrm{P}<0.001$.

phosphatase inhibitors cocktail ( $1 \mathrm{mM}$ sodium fluoride and $1 \mathrm{mM}$ sodium orthovanadate) for $30 \mathrm{~min}$ on ice, and then centrifuged at $12,000 \mathrm{rpm}$ for $15 \mathrm{~min}$ at $4^{\circ} \mathrm{C}$. Supernatants were collected, and equal amounts of denatured proteins (heated samples at $100^{\circ} \mathrm{C}$ for $10 \mathrm{~min}$ ) were separated by SDS-PAGE and transferred to PVDF membranes (Millipore, Bedford, MA, USA), blocked with $5 \%$ nonfat milk at room temperature for $1 \mathrm{~h}$, and incubated with the respective specific primary antibodies overnight at $4^{\circ} \mathrm{C}$. The membranes were washed three times with Tris-buffered saline-5\% Tween-20 (TBST) solution and incubated with a horseradish peroxidase-conjugated secondary antibody at room temperature for $2 \mathrm{~h}$. Chemiluminescent detection was performed by ECL (Bio-Rad, USA).

Statistical analysis. All data are expressed as the mean \pm SD of three independent experiments. Statistical significance was analyzed using a Student's t-test. The criterion of statistical significance was ${ }^{* *} \mathrm{p}<0.01 ;{ }^{* * *} \mathrm{p}<0.001$.

\section{Results}

EO shows significant cytotoxicity against the MDA-MB-468 cells. To evaluate the anti-proliferative effect of EO in MDA-MB-468 human breast cancer cells, the cells were treated with indicated concentrations of EO for 24,48 and $72 \mathrm{~h}$. The cytotoxic effect was measured by MTT assay. As shown in Fig. 1B, EO induced cytotoxicity in the MDA-MB-468 cells in a concentration- and time-dependent manner. $\mathrm{IC}_{50}$ at $72 \mathrm{~h}$ was $1.04 \mu \mathrm{M}$. The effects of EO on the MDA-MB-468 cells may be the result of the induction of apoptosis and/or inhibition of growth. Therefore, the authors investigated whether EO induces apoptosis in human breast cancer cells. 

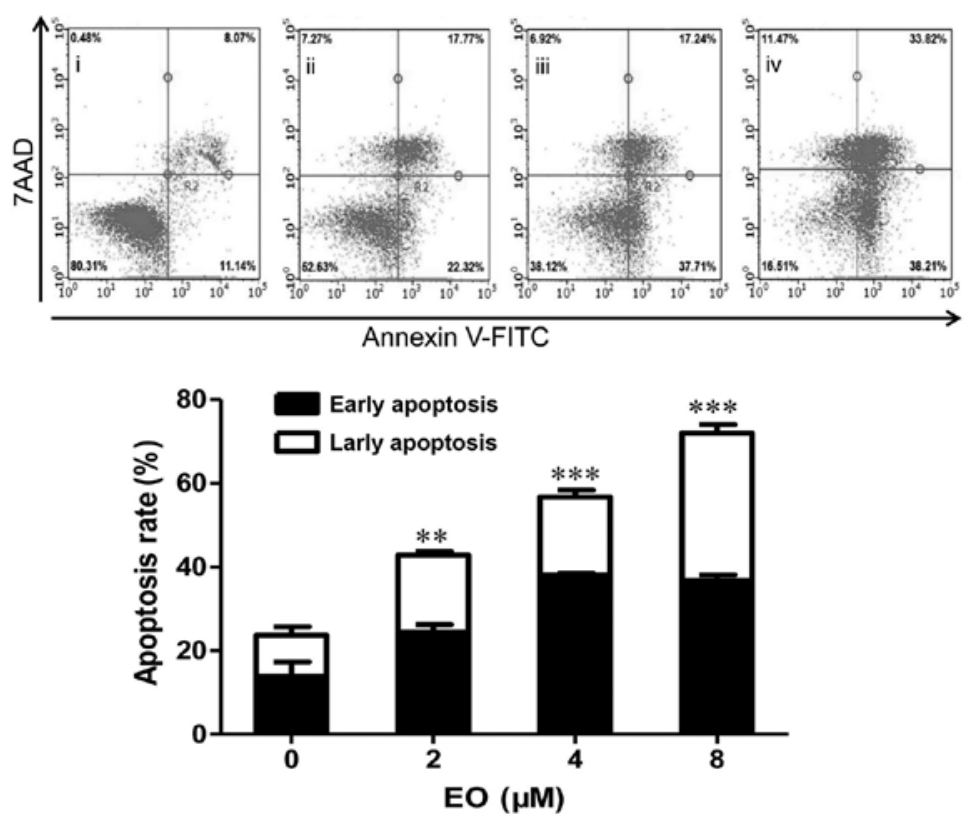

Figure 2. Effects of Eupalinomide O (EO) on apoptotic cell death in MDA-MB-468 cells. The MDA-MB-468 cells were treated with (i) 0 , (ii) 2 , (iii) 4 and (iv) $8 \mu \mathrm{M}$ of EO for $24 \mathrm{~h}$. Then the treated cells were washed twice with ice-cold PBS and stained with Annexin-V-FITC/7AAD according to the manufacturer's instructions. Samples were subsequently analyzed by flow cytometer. Quantified histograms display the effect of EO on MDA-MB-468 cell apoptosis. Data are presented as the mean $\pm \mathrm{SD}$ of three independent experiments. ${ }^{* *} \mathrm{P}<0.01,{ }^{* * *} \mathrm{P}<0.001$.
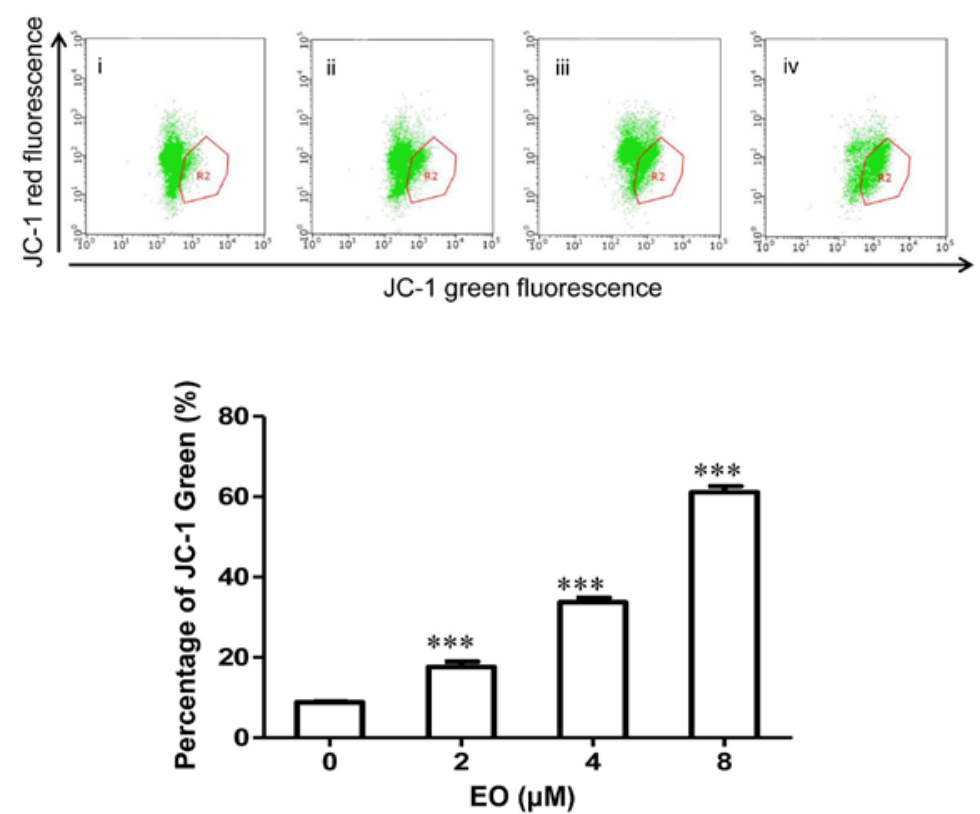

Figure 3. Effects of Eupalinomide O (EO) on mitochondrial membrane potential $(\Delta \psi \mathrm{m})$. MDA-MB-468 cells $\left(3 \times 10^{5}\right)$ were seeded in 6-well plates for $24 \mathrm{~h}$ before the experiment. After the treatment with 2,4 , and $8 \mu \mathrm{M}$ of EO for $24 \mathrm{~h}$, the cells were harvested, washed twice with ice-cold PBS, and incubated with JC-1 $(10 \mu \mathrm{g} / \mathrm{ml})$ in the dark for $15 \mathrm{~min}$ at $37^{\circ} \mathrm{C}$. The cells were washed three times with ice-cold PBS and analyzed by flow cytometry using emission wavelengths of $590 \mathrm{~nm}$ and $529 \mathrm{~nm}$. Data are presented as the mean $\pm \mathrm{SD}$ of three independent experiments. ${ }^{* * *} \mathrm{P}<0.001$.

EO induces apoptosis in the MDA-MB-468 cells. To further determine whether the growth-inhibitory effect of EO was related to the induction of apoptosis, treated cells were analyzed using Annexin V-FITC/7AAD staining by flow cytometric analysis. As shown in Fig. 2, after incubation with EO, the percentage of apoptotic cells was significantly increased. These results indicated that the induction of apoptotic cell death can be a potential mechanism of the anticancer effect of EO against human breast cancer cells.
Treatment of EO results in loss of mitochondrial membrane potential $(\Delta \psi m)$. The $\Delta \psi \mathrm{m}$ is an early event preceding caspase activation, and is regarded as a hallmark of apoptosis (18). Induction of apoptosis via mitochondrial pathways results in the loss of mitochondrial membrane potential. Therefore, we measured $\Delta \psi \mathrm{m}$ in EO-treated MDA-MB-468 cells using the membrane-permeable JC-1 dye. In apoptotic cells with low $\Delta \psi \mathrm{m}, \mathrm{JC}-1$ remains in the monomeric form, which has green fluorescence (19). As shown in Fig. 3, a marked increase in 


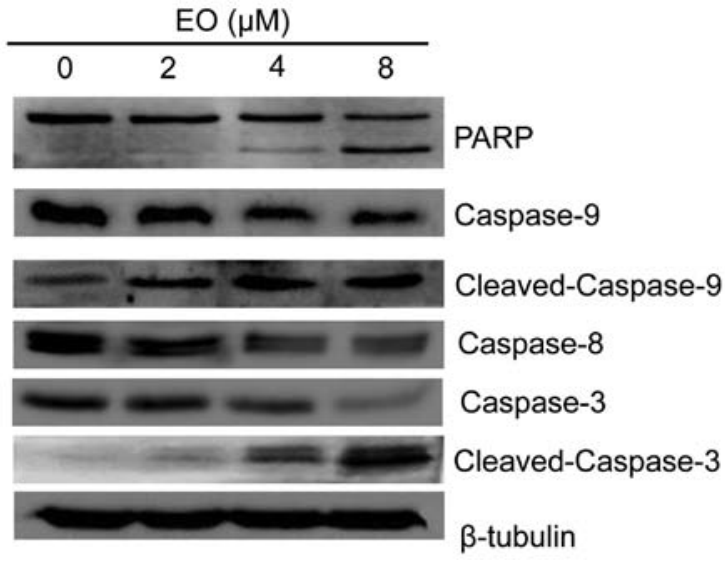

Figure 4. Effects of Eupalinomide O (EO) on the activities of caspases in the MDA-MB-468 cells. The cells were treated with $0,2,4$ and $8 \mu \mathrm{M}$ of EO for $24 \mathrm{~h}$. The cell lysates were collected and subjected to western blot analysis to detect the expression of caspase-3, caspase-8, caspase- 9 and poly(ADP-ribose) polymerase (PARP). Results are representative of at least three independent experiments showing similar results.

green fluorescence could be seen in the MDA-MB-468 cells treated with 2, 4 and $8 \mu \mathrm{M}$ of EO. These results demonstrated that $\mathrm{EO}$ induced $\Delta \psi \mathrm{m}$ disruption in breast cancer cells.
EO induces apoptosis in the MDA-MB-468 cells by activation of caspases. As known the activation of caspases plays important roles in cancer cell death. To confirm whether caspases are involved in EO-induced MDA-MB-468 cell death, we next examined the activation of caspases and the expression of poly(ADP-ribose) polymerase (PARP) by western blot analysis. As shown in Fig. 4, EO treatment significantly decreased the protein levels of pro-caspase-3, pro-caspase- 8 and pro-caspase-9, while increasing the protein levels of cleaved caspase- 3 and caspase-9. To further investigate the enzymatic activation of caspase- 3 , we measured cleaved PARP which is a substrate of caspase-3 and an enzyme that protects DNA. The formation of the fragment of PARP was detected in cells treated with EO (Fig. 4). These results demonstrated that EO induced apoptosis in the MDA-MB-468 cells by the activation of caspases.

EO induces apoptosis in a caspase-dependent manner. To further investigate the role of caspase activation in EO-induced apoptosis, the effect of the pan-caspase inhibitor Z-VAD-FMK in preventing EO-induced cell death was examined. As shown in Fig. 5A, when cells were treated with $8 \mu \mathrm{M}$ of EO, the percentage of apoptotic cells reached $65.01 \%$ at $24 \mathrm{~h}$. However, when cells were pre-treated with caspase
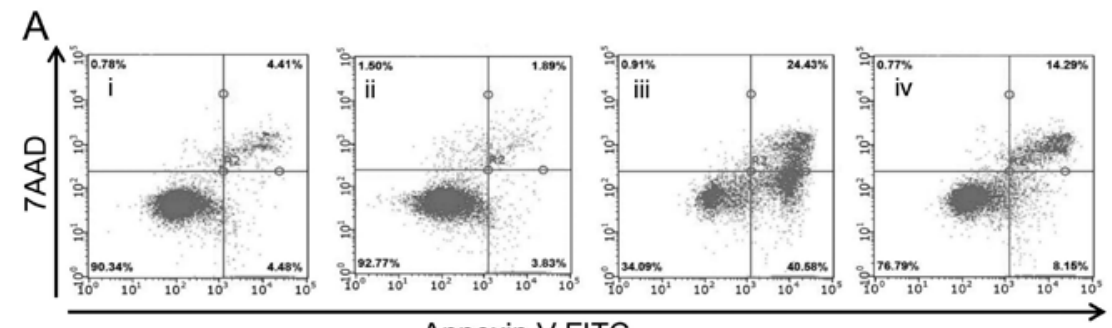

Annexin V-FITC
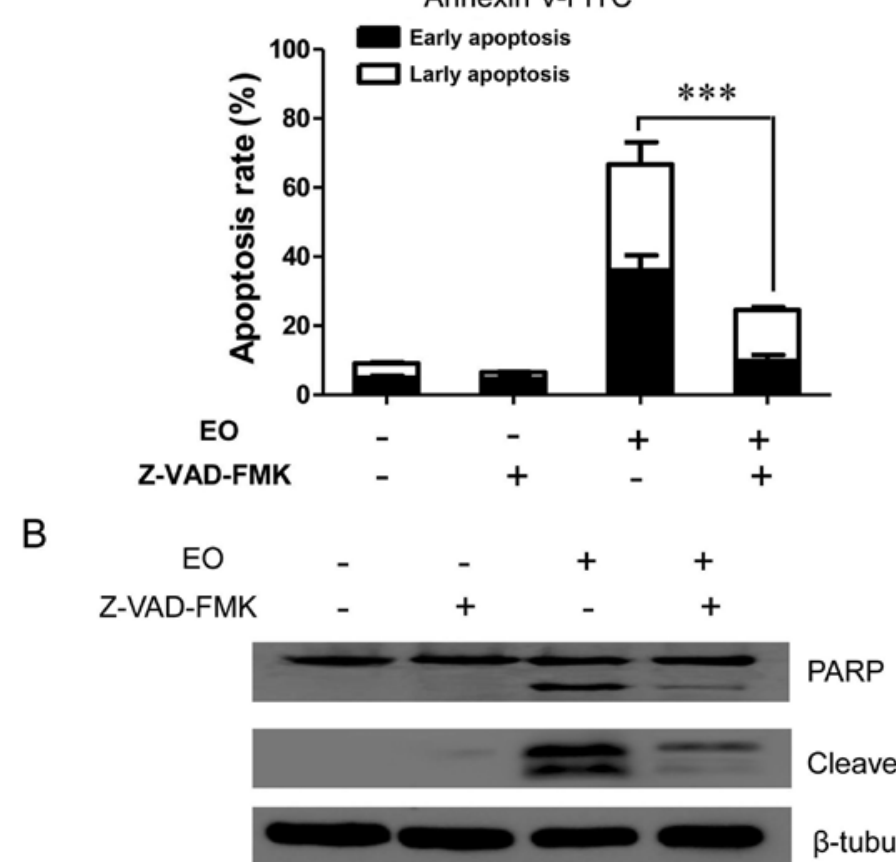

Cleaved caspase-3

$\beta$-tubulin

Figure 5. Effects of the pan-caspase inhibitor Z-VAD-FMK on Eupalinomide O (EO)-induced apoptosis. (A) The cells were pre-treated with $20 \mu \mathrm{M}$ Z-VAD-FMK for $2 \mathrm{~h}$. Subsequently, $8 \mu \mathrm{M}$ of EO was added, and the cells were treated for another $24 \mathrm{~h}$. Then the cells were stained with Annexin-VFITC/7AAD and analyzed by flow cytometry. Image data are representative of three individual experiments. (B) Western blot analysis of caspase-3 and poly(ADP-ribose) polymerase (PARP) in the MDA-MB-468 cells after the treatment of EO and Z-VAD-FMK. All the data above are presented as mean \pm SD. ${ }^{* * * *} \mathrm{P}<0.001$. 

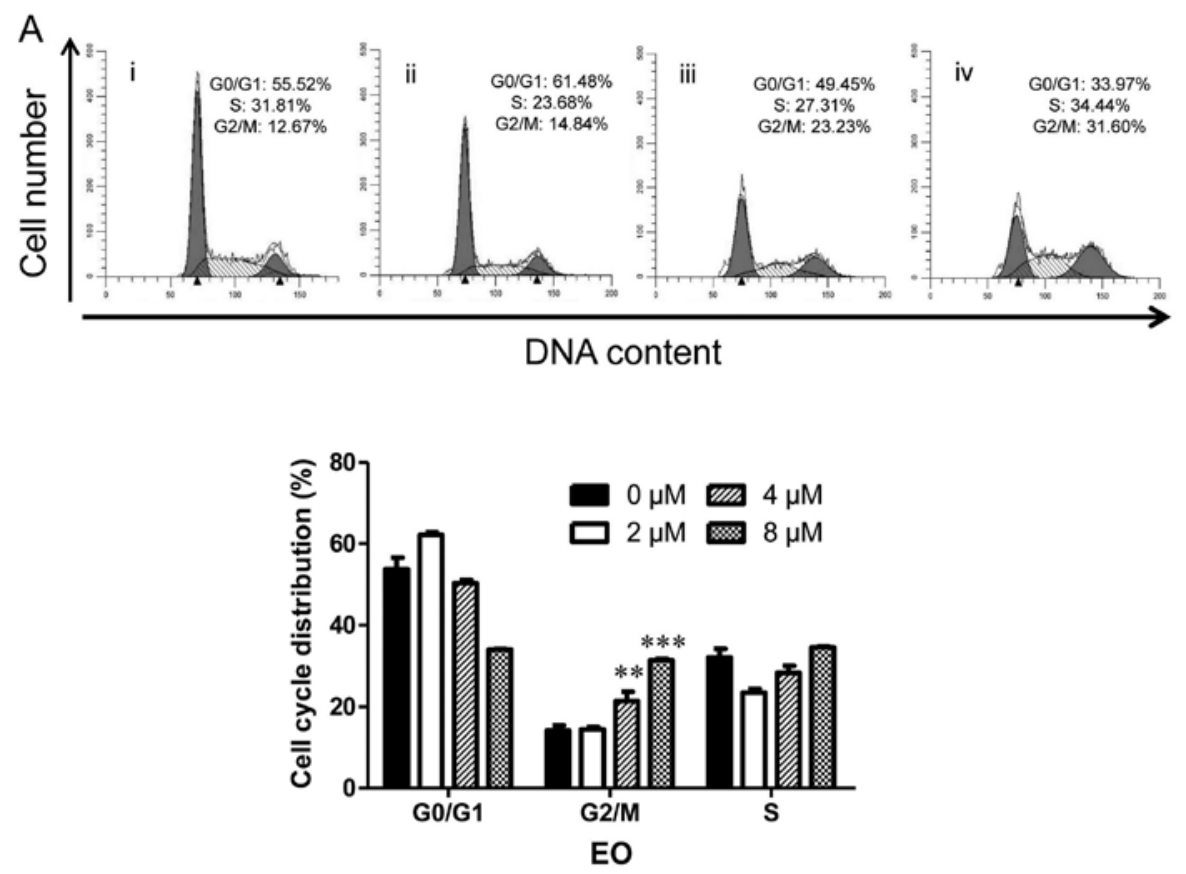

B

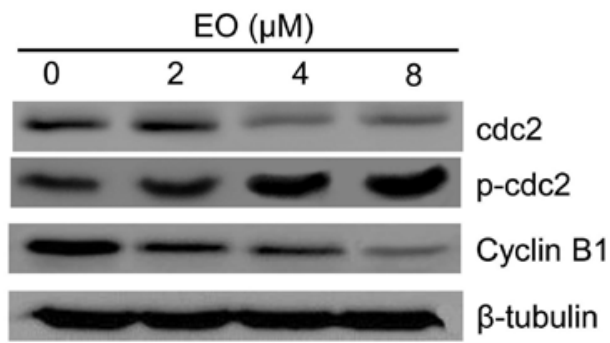

Figure 6. Effect of Eupalinomide O (EO) on the cell cycle in the MDA-MB-468 cells. (A) MDA-MB-468 cells were treated with (i) 0 , (ii) 2 , (iii) 4 and (iv) $8 \mu$ M EO for $24 \mathrm{~h}$, fixed in $70 \%$ ethanol at $4^{\circ} \mathrm{C}$ overnight and stained with propidium iodide (PI). The cell cycle distribution was assessed by flow cytometry. Data are presented as the mean \pm SD of three independent experiments. Quantified histograms display the effect of EO on MDA-MB-468 cell cycle distribution. (B) The expression of the G2/M phase-related proteins, cdc2 and cyclin B1 in the MDA-MB-468 cancer cells was analyzed by western blot analysis. Data are presented as the mean \pm SD of three independent experiments. ${ }^{* *} \mathrm{P}<0.01$ and ${ }^{* * *} \mathrm{P}<0.001$.

inhibitor Z-VAD-FMK for $2 \mathrm{~h}$, the percentage of apoptotic cells was reduced to $22.44 \%$ after $24 \mathrm{~h}$. Moreover, western blot analysis showed that cleavage of caspase-3 and PARP were inhibited (Fig. 5B). These results indicated that EO induced apoptosis mainly by caspase-dependent mechanisms in the MDA-MB-468 cells.

EO induces cell cycle arrest in the MDA-MB-468 cells. To investigate whether EO modulates the cell cycle of the MDA-MB-468 cells, the cells were treated with the indicated concentrations $(0,2,4$ and $8 \mu \mathrm{M})$ of EO for $24 \mathrm{~h}$. The detection of cell cycle distribution was performed by flow cytometry. As shown in Fig. 6A, the G2/M phase distribution was increased from $12.67 \%$ in the vehicle control group to $31.60 \%$ in a concentration-dependent manner after $8 \mu \mathrm{M}$ of EO treatment. To elucidate the molecular mechanism, we next detected the expression of key molecules (cyclin B1, cdc2 and p-cdc2) which regulate the $\mathrm{G} 2 / \mathrm{M}$ phase transition in the EO-treated MDA-MB-468 cells. As shown in Fig. 6B, treatment with EO decreased the protein levels of cyclin B1 and cdc2 while increasing the protein level of p-cdc2 (Tyr15) in a dose-dependent manner. These results suggested that the cell cycle arrest in $\mathrm{G} 2 / \mathrm{M}$ phase may be associated with the anticancer effect of EO on human breast cancer cells.

EO regulates the $B c l-2$ family of proteins and the Akt signaling pathways in the MDA-MB-468 cells. The Bcl-2 family of proteins, such as Bcl-2 and Bax, are upstream signals of caspase activation and play important roles in regulating mitochondrial-related apoptosis (20). The Bcl-2 family includes anti-apoptotic and pro-apoptotic proteins. The release of proteins from the inner-membrane space of mitochondria is one of the central events in the apoptotic process, which can lead to the activation of caspases and the ultimate demise of the cell (21). To elucidate further the anticancer mechanism, the role of the Bcl-2 family of proteins in EO-induced apoptosis was investigated. As shown in Fig. 7, after treatment with EO, the expression of anti-apoptotic Bcl-xl and Bcl-2 was significantly decreased, and the expression of pro-apoptotic Bax and Bad was increased. Collectively, these results suggest that EO may induce apoptosis of the MDA-MB-468 cells through Bcl-2 degradation.

To further explore the possible mechanism of EO on the induction of apoptosis in breast cancer cells, we assessed its 


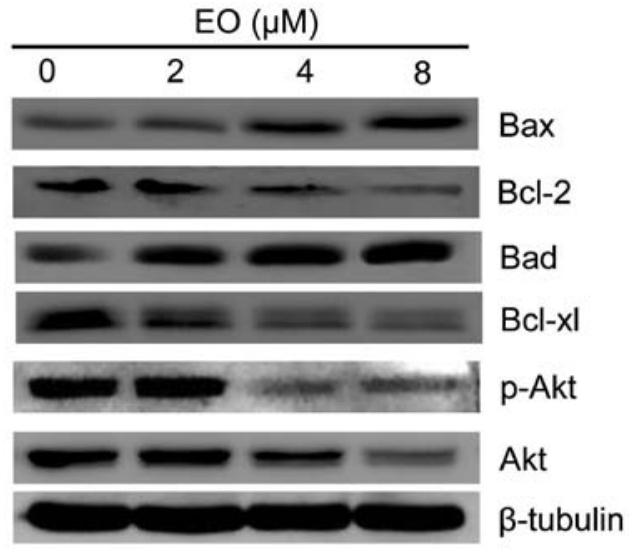

Figure 7. Effects of Eupalinomide O (EO) on the Bcl-2 family of proteins and the Akt signaling pathway in the MDA-MB-468 cells by western blot analysis. The cells were treated with $0,2,4$ and $8 \mu \mathrm{M}$ of EO for $24 \mathrm{~h}$. The cell lysates were collected and subjected to western blot analysis to detect the expression of Bcl-xl, Bax, Bcl-2, Bad and Akt. Results are representative of at least three independent experiments showing similar results.

effect on the Akt signaling pathways. The Akt signaling pathways have been shown to be critical regulators of cell growth, differentiation and survival $(22,23)$. Sesquiterpene lactones can promote cancer cell survival by activating the PI3K/Akt pathway (24). The Akt pathway is a major anti-apoptotic signaling pathway, and previous studies have shown that chemotherapy drugs induce apoptosis of tumor cells by inhibiting the Akt pathway (25-27). Thus, we determined the protein expression of Akt in the MDA-MB-468 cells and found that $\mathrm{EO}$ significantly reduced the expression of both Akt and p-Akt which is an active form of Akt in a dose-dependent manner (Fig. 7). These data suggest that the Akt pathway may be an effective target for EO in the MDA-MB-468 cells.

\section{Discussion}

In the present study, the authors investigated the anticancer effects of EO against the MDA-MB-468 breast cancer cells. EO induced apoptotic cell death in the MDA-MB-468 cells through cell cycle arrest in the G2/M phase (Fig. 6), activation of caspases (Fig. 4), and disruption of the mitochondrial membrane potential $(\Delta \psi \mathrm{m})$ (Fig. 3). Notably, the effect of EO in the induction of apoptosis was in a caspase-dependent manner (Fig. 5). Furthermore, the Akt signaling pathway in the MDA-MB-468 cells was suppressed which may play a critical role in EO-induced apoptosis (Fig. 7).

The induction of cell cycle arrest and apoptosis are common mechanisms proposed for the cytotoxic effects of anticancer drugs (28). Cell cycle arrest can trigger proliferation inhibition and apoptosis in cancer cells $(29,30)$. During the cell cycle, the $\mathrm{G} 2 / \mathrm{M}$ checkpoint is a potential target for cancer therapy, and cdc2/cyclin B1 are critical and complex regulators at the $\mathrm{G} 2 / \mathrm{M}$ phase (31). Some anticancer drugs induce G2/M arrest through the downregulation of the expression of cyclin B1 and cdc2 (32). In our study, the results showed that EO treatment resulted in $\mathrm{G} 2 / \mathrm{M}$ arrest and decreased expression of cdc2 and cyclin B1, suggesting that a decrease of cyclin B1 and cdc2 expression may be the molecular mechanism through which $\mathrm{EO}$ induced $\mathrm{G} 2 / \mathrm{M}$ arrest.
Apoptosis regulates biological processes that play an important role in homeostasis, development and elimination of damaged cells. Apoptosis in cancer cells can be a promising treatment method in cancer therapy. In general, drug-induced apoptosis is one major mechanism of action for the treatment of cancer, and various signaling pathways are involved in the process. It is well known that the two main signaling pathways that induce apoptosis are the mitochondrial-mediated intrinsic and death receptor-mediated extrinsic pathways (33). The activation of caspase protease is the basis of cell apoptosis. In some cells, these cysteine proteases can directly cleave and activate caspase- 3 to induce apoptosis in the executive phase (34). After the activation of caspase-3, several specific substrates including PARP cleavage, eventually lead to apoptosis (35). Consistent with the above notion, in this study, EO treatment significantly decreased the protein levels of pro-caspase-3, pro-caspase-8, pro-caspase-9 and PARP while increasing the protein levels of cleaved caspase-3, caspase-9 and PARP (Fig. 4). These results demonstrated that EO induced apoptosis by triggering the intrinsic and extrinsic apoptotic pathways in the MDA-MB-468 cells. Notably, the effect on the induction of apoptosis may be prevented by the treatment of the pan-caspase inhibitor Z-VAD-FMK.

The $\Delta \psi \mathrm{m}$ is an early event preceding caspase activation, and is regarded as a hallmark of apoptosis (18). Induction of apoptosis via the mitochondrial pathways results in the loss of mitochondrial membrane potential. In addition, the mitochondrial-mediated intrinsic apoptotic pathway is regulated by the proteins of the Bcl-2 family (36). Indeed, we found that EO decreased $\Delta \psi \mathrm{m}$ in the MDA-MB-468 cells (Fig. 3) and downregulated the expression of anti-apoptotic Bcl-xl and Bcl-2 while upregulating that of pro-apoptotic Bax and Bad (Fig. 7), indicating that the loss of $\Delta \psi \mathrm{m}$ plays an important role in EO-induced apoptosis in breast cancer cells. These results indicate that EO induces apoptosis of breast cancer cells through the induction of mitochondrial dysfunction caused by deregulation of the Bcl-2 family proteins.

The PI3K/Akt signaling pathway is a critical transduction pathway which plays an important role in the regulation of cell proliferation, cell cycle and apoptosis (37). Recent studies have demonstrated that various anticancer drugs induce $\mathrm{G} 2 / \mathrm{M}$ arrest accompanied by downregulation of Akt $(38,39)$. Furthermore, it is reported that the PI3K/Akt pathway also participates in the regulation of the Bcl-2 family proteins, which are key regulators of the apoptotic pathway (40). In our study, the expression of the Akt pathway was significantly suppressed in the MDA-MB-468 cells following treatment with EO.

In conclusion, this study has shown for the first time that $\mathrm{EO}$, a novel sesquiterpene lactone, caused the inhibition of the proliferation of breast cancer MDA-MB-468 cells through cell cycle arrest and induction of apoptosis. The apoptotic cell death response was found to be caspase-dependent. Furthermore, the inhibition of the Akt signaling pathway may play a vital role in EO-induced apoptosis. These results clearly indicate that EO is a promising anticancer agent against breast cancer.

\section{Acknowledgements}

This study was financially supported by the Zhejiang Provincial Natural Science Fund (no. LZ15H310001), the 
Zhejiang Province Chinese Medicine Scientific Research Fund Project (no. 2016ZA050), the Young Scholar Program of Students' Scientific and Technological Innovation Activities in Zhejiang's Universities (no. 2015R410025) and the Zhejiang Chinese Medical University Research Fund Project (no. 2015ZR06). We extremely thank our team members Rui Zhu, Sha-Sha Tian and Zhi-Hui Zhu from Zhejiang Chinese Medical University for their technical support.

\section{References}

1. Jemal A, Bray F, Center MM, Ferlay J, Ward E and Forman D: Global cancer statistics. CA Cancer J Clin 61: 69-90, 2011.

2. Yasemi M, Ahmadi MRH, Khajavikhan J, Peyman H, Asadollahi KH, Yasemi MR and Hemati K: An 8 years retrospective study of breast cancer incidence in Ilam province, Western Iran. J Clin Diagn Res 7: 2923-2925, 2013.

3. Howard JH and Bland KI: Current management and treatment strategies for breast cancer. Curr Opin Obstet Gynecol 24: 44-48, 2012.

4. Are C, Rajaram S, Are M, Raj H, Anderson BO, Chaluvarya Swamy R, Vijayakumar M, Song T, Pandey M, Edney JA, et al: A review of global cancer burden: Trends, challenges, strategies, and a role for surgeons. J Surg Oncol 107: 221-226, 2013.

5. Head J and Johnston SR: New targets for therapy in breast cancer: Farnesyltransferase inhibitors. Breast Cancer Res 6: 262-268, 2004

6. Mann J: Natural products in cancer chemotherapy: Past, present and future. Nat Rev Cancer 2: 143-148, 2002.

7. Koehn FE and Carter GT: The evolving role of natural products in drug discovery. Nat Rev Drug Discov 4: 206-220, 2005.

8. Newman DJ and Cragg GM: Natural products as sources of new drugs over the 30 years from 1981 to 2010. J Nat Prod 75: 311-335, 2012.

9. Cragg GM and Newman DJ: Antineoplastic agents from natural sources: Achievements and future directions. Expert Opin Investig Drugs 9: 2783-2797, 2000.

10. Butler MS: The role of natural product chemistry in drug discovery. J Nat Prod 67: 2141-2153, 2004.

11. Kaczirek K, Schindl M, Weinhäusel A, Scheuba C, Passler C, Prager G, Raderer M, Hamilton G, Mittlböck M, Siegl V, et al: Cytotoxic activity of camptothecin and paclitaxel in newly established continuous human medullary thyroid carcinoma cell lines. J Clin Endocrinol Metab 89: 2397-2401, 2004.

12. Huo J, Yang SP, Ding J and Yue JM: Two new cytotoxic sesquiterpenoids from Eupatorium lindleyanum DC. J Integr Plant Biol 48: 473-477, 2006.

13. Ji LL, Luo YM and Yan GL: Studies on the antimicrobial activities of extracts from Eupatorium lindleyanum DC against food spoilage and food-borne pathogens. Food Contr 19: 995-1001, 2008.

14. Ye G, Huang XY, Li ZX, Fan MS and Huang CG: A new cadinane type sesquiterpene from Eupatorium lindleyanum (Compositae). Biochem Syst Ecol 36: 741-744, 2008.

15. Wu SQ, Xu NY, Sun Q, Han HY and Zhang J: Six New sesquiterpenes from Eupatorium lindleyanum. Helv Chim Acta 95: 1637-1644, 2012

16. Wu SQ, Xu NY, Zhang J, Yao S and Chu CJ: Three new acyclic diterpenoids from Eupatorium lindleyanum DC. J Asian Nat Prod Res 14: 652-656, 2012.

17. Ito K, Sakakibara Y, Haruna $M$ and Lee KH: Four new germacranolides from Eupatorium lindleyanum DC. Chem Lett 8: 1469-1472, 1979.

18. Charlot JF, Prétet JL, Haughey C and Mougin C: Mitochondrial translocation of p53 and mitochondrial membrane potential $(\Delta \Psi m)$ dissipation are early events in staurosporine-induced apoptosis of wild type and mutated p53 epithelial cells. Apoptosis 9: 333-343, 2004.

19. Reers M, Smiley ST, Mottola-Hartshorn C, Chen A, Lin M and Chen LB: Mitochondrial membrane potential monitored by JC-1 dye. Methods Enzymol 260: 406-417, 1995.
20. Kajiwara T, Takeuchi T, Ueki T, Moriyama N, Ueki K, Kakizoe T and Kawabe K: Effect of Bcl-2 overexpression in human prostate cancer cells in vitro and in vivo. Int J Urol 6: 520-525, 1999.

21. Henry-Mowatt J, Dive C, Martinou JC and James D: Role of mitochondrial membrane permeabilization in apoptosis and cancer. Oncogene 23: 2850-2860, 2004.

22. Takeda K and Akira S: STAT family of transcription factors in cytokine-mediated biological responses. Cytokine Growth Factor Rev 11: 199-207, 2000.

23. Gottlieb TM, Leal JF, Seger R, Taya Y and Oren M: Cross-talk between Akt, p53 and Mdm2: Possible implications for the regulation of apoptosis. Oncogene 21: 1299-1303, 2002.

24. Farha AK, Dhanya SR, Mangalam SN, Geetha BS, Latha PG and Remani P: Deoxyelephantopin impairs growth of cervical carcinoma $\mathrm{SiHa}$ cells and induces apoptosis by targeting multiple molecular signaling pathways. Cell Biol Toxicol 30: 331-343, 2014.

25. Li MH, Cha YN and Surh YJ: Peroxynitrite induces HO-1 expression via PI3K/Akt-dependent activation of NF-E2-related factor 2 in PC12 cells. Free Radic Biol Med 41: 1079-1091, 2006.

26. Sheppard K, Kinross KM, Solomon B, Pearson RB and Phillips WA: Targeting PI3 kinase/AKT/mTOR signaling in cancer. Crit Rev Oncog 17: 69-95, 2012.

27. Gao L, Wang Y, Xu Z, Li X, Wu J, Liu S, Chu P, Sun Z, Sun B, Lin Y, et al: SZC017, a novel oleanolic acid derivative, induces apoptosis and autophagy in human breast cancer cells. Apoptosis 20: 1636-1650, 2015.

28. Xavier CP, Lima CF, Preto A, Seruca R, Fernandes-Ferreira M and Pereira-Wilson C: Luteolin, quercetin and ursolic acid are potent inhibitors of proliferation and inducers of apoptosis in both KRAS and BRAF mutated human colorectal cancer cells Cancer Lett 281: 162-170, 2009.

29. Pu L, Amoscato AA, Bier ME and Lazo JS: Dual G1 and G2 phase inhibition by a novel, selective Cdc25 inhibitor 7-chloro-6-(2-morpholin-4-ylethylamino)-quinoline-5,8-dione. J Biol Chem 277: 46877-46885, 2002.

30. Chao JI, Kuo PC and Hsu TS: Down-regulation of survivin in nitric oxide-induced cell growth inhibition and apoptosis of the human lung carcinoma cells. J Biol Chem 279: 20267-20276, 2004.

31. Su M, Chung HY and Li Y: 6- $O$-Angeloylenolin induced cell-cycle arrest and apoptosis in human nasopharyngeal cancer cells. Chem Biol Interact 189: 167-176, 2011.

32. Yang CJ, Wang CS, Hung JY, Huang HW, Chia YC, Wang PH, Weng CF and Huang MS: Pyrogallol induces G2-M arrest in human lung cancer cells and inhibits tumor growth in an animal model. Lung Cancer 66: 162-168, 2009.

33. Denault JB and Boatright K: Apoptosis in Biochemistry and Structural Biology. 3-8 February 2004, Keystone, CO, USA. IDrugs 7: 315-317, 2004.

34. Scaffidi C, Fulda S, Srinivasan A, Friesen C, Li F, Tomaselli KJ, Debatin KM, Krammer PH and Peter ME: Two CD95 (APO-1/Fas) signaling pathways. EMBO J 17: 1675-1687, 1998.

35. Lazebnik YA, Kaufmann SH, Desnoyers S, Poirier GG and Earnshaw WC: Cleavage of poly(ADP-ribose) polymerase by a proteinase with properties like ICE. Nature 371: 346-347, 1994.

36. Schwarz M, Andrade-Navarro MA and Gross A: Mitochondrial carriers and pores: Key regulators of the mitochondrial apoptotic program? Apoptosis 12: 869-876, 2007.

37. Kauffmann-Zeh A, Rodriguez-Viciana P, Ulrich E, Gilbert C, Coffer P, Downward J and Evan G: Suppression of c-Myc-induced apoptosis by Ras signalling through PI(3)K and PKB. Nature 385: 544-548, 1997.

38. Katayama K, Fujita $\mathrm{N}$ and Tsuruo T: Akt/protein kinase B-dependent phosphorylation and inactivation of WEE1Hu promote cell cycle progression at $\mathrm{G}_{2} / \mathrm{M}$ transition. Mol Cell Biol 25: 5725-5737, 2005.

39. Weir NM, Selvendiran K, Kutala VK, Tong L, Vishwanath S, Rajaram M, Tridandapani S, Anant S and Kuppusamy P: Curcumin induces $\mathrm{G}_{2} / \mathrm{M}$ arrest and apoptosis in cisplatin-resistant human ovarian cancer cells by modulating Akt and p38 MAPK. Cancer Biol Ther 6: 178-184, 2007.

40. Asnaghi L, Calastretti A, Bevilacqua A, D'Agnano I, Gatti G, Canti G, Delia D, Capaccioli S and Nicolin A: Bcl-2 phosphorylation and apoptosis activated by damaged microtubules require mTOR and are regulated by Akt. Oncogene 23: 5781-5791, 2004. 